\title{
MÚLTIPLOS CORPOS EM MICHEL FOUCAULT
}

\author{
MULTIPLE BODIES IN MICHEL FOUCAULT
}

MÚLTIPLES CUERPOS EN MICHEL FOUCAULT

Oscar Cirino*

\begin{abstract}
RESUMO
Este artigo busca demonstrar como a temática do corpo está presente em grande parte da obra de Foucault e recebe ênfases e desenvolvimentos diferentes conforme a perspectiva metodológica e o foco de suas pesquisas, nos campos do saber, do poder e da ética. No campo do saber médico, encontra-se a perspectiva de uma "anatomia patológica", enquanto, no âmbito das relaçōes de poder, constitui-se uma "anatomia política". Já nos últimos volumes da História da sexualidade, o interesse de Foucault desloca-se das "técnicas disciplinares" para as "técnicas ou práticas de si", desenvolvidas durante a Antiguidade grega e greco-latina. As perspectivas da "estética da existência" e do "cuidado de si" concedem importante lugar ao tema da relação com o corpo, na constituição ética do sujeito. Esse percurso na obra de Foucault atesta sua fidelidade ao que considera ser, por excelência, a atividade filosófica, na atualidade (um trabalho crítico do pensamento sobre o próprio pensamento).
\end{abstract}

Palavras-chave: Foucault. Corpo. Técnicas disciplinares. Práticas de si.

\section{ABSTRACT}

The article intends to demonstrate how the body theme is present in a great part of Foucault's works and it gathers emphasis and different developments according to the methodological perspective and the focus of his researches, in the fields of knowledge, power and ethics. In the field of medical knowledge, is the perspective of a "pathological anatomy", whereas, in the realm power relations, there is a "political anatomy". Furthermore, in the last volumes of the The history of sexuality, Foucault's interest shifts from "disciplinary techniques" towards "techniques or practices of the self" developed during Greek and Greco-Roman Ancient Times. The perspectives of the "Aesthetics of existence" and "The care of the self" bestow an important rank to the theme of the relations with the body in the ethical constitution of the subject. This course in Foucault's works attests his fidelity to what he considers to be, par excellence, the philosophical activity, and currently (a critical work of thinking about thinking itself).

*Mestre e bacharel em Filosofia pela Universidade Federal de Minas Gerais (UFMG), psicanalista. Endereço: Rua dos Aimorés, 2631, ap. 1001 - Santo Agostinho, Belo Horizonte-MG, Brasil. CEP: 30140-076. E-mail: ocirino@uol.com.br. 
Keywords: Foucault. Body. Disciplinary techniques. Self-practices.

\section{RESUMEN}

La temática del cuerpo está presente en gran parte de la obra de Foucault y recibe énfasis y desarrollos distintos según la metodología y el enfoque de sus investigaciones en los campos del saber, del poder y de la ética. En el primero encontramos la perspectiva de una "anatomía patológica", mientras que en el segundo hallamos la "anatomía política". Por fin, en los últimos volúmenes de Historia de la sexualidad el interés de Foucault pasa de las "técnicas disciplinarias" a las "técnicas o prácticas de sî", desarrolladas a lo largo de la Antigüedad griega y grecolatina. Las perspectivas de la "estética de la existencia" y del "cuidado de sí" dan importante lugar al tema de la relación con el cuerpo, en la constitución ética del sujeto. Ese recorrido por la obra de Foucault comprueba su fidelidad a lo que considera ser por excelencia la actividad filosófica hoy: un trabajo crítico del pensamiento sobre sí mismo.

Palabras clave: Foucault. Cuerpo. Técnicas disciplinarias. Prácticas de sí.

A temática do corpo está presente em grande parte da obra de Foucault e recebe ênfases e desenvolvimentos diferentes conforme a perspectiva metodológica e o foco de suas pesquisas, nos campos do saber, do poder e da ética.

\section{DA ANATOMIA PATOLÓGICA À ANATOMIA POLÍTICA}

E m um de seus primeiros livros, O nascimento da clínica, de 1963, Foucault (1980) busca entender as condições de possibilidade, no início do século XXIX, do "grande corte na história da medicina ocidental" (p. 167), quando ela se liberta do medo da morte. Trata-se do advento de sua figura propriamente moderna, científica: a anatomoclínica. A doença deixa, então, de ser uma essência nosológica, uma espécie natural, estudada segundo o modelo da botânica, para ser considerada, segundo o modelo da anatomia, como uma realidade localizada no espaço concreto, individual do organismo doente. "Técnica do cadáver", a anatomia patológica faz, desse resto inanimado do corpo humano, a fonte da verdade da vida. ${ }^{1}$

Em 1966, com As palavras e as coisas, Foucault desenvolve a "analítica da finitude" do homem, como um duplo empírico-transcendental, considerando as formas positivas do modo de ser do trabalho, da vida e da linguagem. No

\footnotetext{
1 Essa atenção do médico ao singular, ao que é próprio de cada corpo, é o que fará Lacan referir-se a esse livro de Foucault, destacando que, estruturalmente, a clínica psicanalítica encontra sua especificidade nesse momento inaugural da clínica médica, "momento originalmente recalcado no médico que a prorroga, transformando-se ele mesmo, a partir desse momento, cada vez mais no filho perdido" (Lacan, 1998, p. 326, nota 2).
} 
caso da vida (ao mesmo tempo núcleo do ser e do não ser), a limitação concreta da existência do homem se encontra na finitude do próprio corpo, que com "sua espacialidade própria e irredutível se articula [...] com o espaço das coisas" (Foucault, 1985, p. 330). ${ }^{2}$

Será, entretanto, a partir da década de 1970, quando ocorre um deslocamento de perspectiva na obra de Foucault, desde uma reformulação política, teórica e metodológica, que o corpo recebe maior destaque, por se constituir num dos alvos privilegiados das relaçóes de saber e poder (Machado, 1982). Trata-se, agora, não mais de uma anatomia patológica, mas de uma "anatomia política" e da "lenta formação de um saber e de um poder de normalização" (Foucault, 2001, p. 419).

$\mathrm{Na}$ série de revoltas ocorridas nas prisões francesas nas décadas de 1960 e 1970, Foucault constata algo de paradoxal nas reivindicações e objetivos desses movimentos: eram revoltas não somente contra a miséria física das prisões (fome, frio, superlotação, maus-tratos), mas também contra as "prisões-modelos, contra os tranquilizantes, contra o isolamento, contra o serviço médico ou educativo" (Foucault, 1975, p. 35). Não se tratava apenas de lutas contra o aspecto decadente e desumano das prisóes, mas também contra o seu aperfeiçoamento e modernização. Para Foucault, o que haveria de comum entre esses protestos, à primeira vista distintos, seria o fato de que ambos se rebelavam contra o investimento de poder ao nível do corpo.

A fim de compreender essa "anatomia política", ele realiza, em Vigiar e punir (Foucault, 1975), ${ }^{3}$ uma análise histórica de diferentes sistemas punitivos, desde os que utilizam métodos violentos até os que empregam procedimentos "suaves", não tomando, entretanto, como referência a evolução das regras do Direito ou das ideias morais. Foucault parte do pressuposto de que todo poder tem um "corpo", pois se exerce fisicamente por diferentes mecanismos e instrumentos, sejam eles cadafalsos, cerimônias, muros, olhares, medicamentos ou diagnósticos e, ao mesmo tempo, inscreve-se sobre os corpos em sua materialidade. Sua "história dos corpos" se distingue, portanto, de uma "história das mentalidades", pois não se limita a considerar como os corpos foram percebidos e valorizados historicamente, mas busca pesquisar como "se investiu sobre o que há neles de mais material, de mais vivo" (Foucault, 1976, p. 200). Dessa maneira, ele quer explicitar como "as relações de poder operam sobre [o corpo] de modo imediato; elas o investem, marcam-no, dirigem-no, supliciam-no, submetemno a trabalhos, obrigam-no a cerimônias, exigem-lhe sinais" (Foucault, 1975, p. 30).

\footnotetext{
2 Os tópicos sobre "a analítica da existência" e sobre o homem como um "empírico e transcendental" se encontram no capítulo IX de As palavras e as coisas (Foucault, 1985, pp. 328-338).

3 Em Vigiar e punir, encontramos capítulos com os seguintes títulos: "o corpo dos condenados" (em oposição ao famoso "corpo do rei") e "os corpos dóceis", constituídos a partir das técnicas disciplinares.
} 
Podemos postular que Foucault se afasta radicalmente de uma perspectiva naturalista do corpo, pois, para ele, o corpo não tem estruturas e necessidades fixas, mas pode ser modificado, aperfeiçoado, e suas necessidades, produzidas e organizadas de diferentes maneiras. Em suma, o corpo é "maleável", flexível, formado por diversos hábitos, valores e práticas, estando, portanto, inscrito no registro da história e não apenas da natureza. Essa concepção traz a marca do pensamento nietzschiano, pois, segundo Foucault, a genealogia é um tipo de história que não se pauta na consciência ou no eu (com sua unidade e coerência), mas no corpo e em tudo que se relaciona com ele: a alimentação, o clima, os valores. O corpo, "lugar de dissolução do eu", "volume em perpétua pulverização", traz consigo "em sua vida e em sua morte, em sua força e em sua fraqueza”, a inscrição de todos os acontecimentos e conflitos, erros e desejos (Foucault, 1982, p. 22).

Além dessa influência de Nietzsche, as elaborações de Foucault também estariam, segundo Dreyfus e Rabinow, marcadas pelas reflexôes desenvolvidas por Merleau-Ponty na Fenomenologia da percepção (1945), especialmente as relacionadas às estruturas invariantes existentes no corps vécu. Entretanto essas constantes seriam muito gerais para dar conta da especificidade histórica com que Foucault descreve as técnicas de constituição do corpo. Ainda que ele não estabeleça claramente até que ponto o corpo pode ser modelado, mantendose "evasivo" com relação à extensão das modificações impostas pelas técnicas do poder disciplinar. Em suma, mesmo percebendo as influências de Nietzsche e Merleau-Ponty, é difícil determinar com exatidão a concepção de corpo em Foucault, nesse momento de suas investigações (Dreyfus \& Rabinow, 1984, pp. 164-166).

Nas pesquisas que desenvolveu em seu curso de 1973 e 1974, no Collège de France, ${ }^{4}$ sobre $O$ poder psiquiátrico, Foucault indica que a característica "marcante" desse poder é sua "organização [...] em torno e a partir do corpo do psiquiatra” (Foucault, 2006b, p. 275).

Essa "dissimetria essencial do poder" se apresenta, já de início, na pessoa do psiquiatra, em carne e osso, que se impóe fisicamente por seu porte impecável, sua plástica, suas palavras firmes e seus gestos nítidos. Esse corpo, articulado às "marcas do seu saber", está presente em todo o espaço asilar, em comunicação direta com todas as partes da administração, em todas as suas engrenagens.

No início do século XIX, a prática da internação coincide com o momento em que a loucura é percebida mais em relação à conduta regular e normal do que em relação a um erro da razão ou a uma ilusão (Foucault, 2006a, p. 443). Isso

4 A íntegra dos cursos de Michel Foucault no Collège de France somente começou a ser publicada na França em 1997, 13 anos depois de sua morte. Antes disso, apenas tínhamos acesso ao Resumo dos cursos, publicados em 1989. 
estabelecerá as condições para que um processo de luta e de oposição se estabeleça entre a vontade do doente e a "vontade reta" do médico, com a dominação e vitória deste último. Assim, a repartição dos doentes no espaço asilar, suas maneiras de se comportar, suas necessidades, seus prazeres estarão submetidos a essa "espécie de microfísica dos corpos" (Foucault, 2006a, p. 19).

Como esclarece Jacques Lagrange, ao situar esse curso de 1973 e 1974, o poder psiquiátrico analisado por Foucault apresenta um "duplo caráter". Por um lado, tem, em última instância, como indicamos, os corpos como alvo de aplicação. Por outro, as relações de poder que se estabelecem entre o psiquiatra e seu paciente

São essencialmente instáveis, constituídas de lutas e enfrentamentos, em que a todo instante estão presentes pontos de resistência. É o caso dessas 'contramanobras' pelas quais as histéricas minam o poder de Charcot, escapando das categorizações que este queria assinálas [...] (Lagrange, 2006, p. 477). ${ }^{5}$

Essa é, como sabemos, a perspectiva foucaultiana sobre as relações de poder: o poder não é aquilo que alguém detém, tampouco é o que emana de alguém, mas sim um confronto que implica linhas de força e de fragilidade, possíveis pontos de resistência ou ataque, estabelecidos na "dispersão, [nas] intermediações, redes, apoios recíprocos, diferenças de potencial, defasagens" (Foucault, 2006b, p. 7).

\section{A "carne" e o corpo das crianças}

Em seu curso de 1974 e 1975 no Collège de France, intitulado Os anormais, a apresentação de algumas de suas pesquisas nos fornece certa ideia do que Foucault estava elaborando sobre determinados pontos que constituiriam alguns volumes do projeto inicial abortado da História da sexualidade (Foucault, 1976). ${ }^{6}$

Nesse sentido, retomaremos algumas indicações mais diretamente relacionadas ao tema do corpo, como as questões da "carne" e da masturbação, que iriam ser desenvolvidas nos volumes 2 e 3, respectivamente, $A$ carne e o corpo e $A$ cruzada das crianças.

A nova pastoral nascida da Reforma Protestante e da Reforma da Igreja Católica, a partir do século XVI, implicou importantes mudanças nas práticas penitenciais, no exame de consciência e nas técnicas de direção espiritual. Segundo

\footnotetext{
5 No curso O poder psiquiátrico, Foucault (2006b) desenvolve outras duas noções de corpo: o corpo neurológico e o corpo sexual, diferenciando-os do corpo anatomopatológico e do corpo disciplinar da psiquiatria (p. 419). O corpo neurológico implica a descoberta de um corpo que "não é simplesmente um corpo de órgãos e tecidos, mas um corpo com funções, desempenhos e comportamentos" (Foucault, 2006b, pp. 373, 387-389). Já o corpo sexual, fruto da "grande batalha entre o neurologista e o histérico", viabilizará a possibilidade de a medicina "agir sobre a sexualidade" (p. 419).

$6 \mathrm{O}$ projeto inicial é anunciado na contracapa da primeira edição francesa e constava de seis volumes. Além de $A$ vontade de saber (vol. 1), teríamos A carne e o corpo (vol. 2); A cruzada das crianças (vol. 3); A mulher, a mãe e a histérica (vol. 4); Os perversos (vol. 5); e População e raças (vol. 6). Segundo um dos biógrafos de Foucault, Eribon (1990, p. 255), Foucault já tinha muito material pesquisado e planejava lançar um novo volume a cada três meses.
} 
Foucault: "Todos os novos procedimentos e regras de confissão desenvolvidos desde o concílio de Trento - essa espécie gigantesca de interiorização, no discurso penitencial, da vida inteira dos indivíduos - na verdade são secretamente focados no corpo e na masturbação" (Foucault, 2001, p. 244).

A "carne" é o nome dessa interioridade do corpo, ou seja, ela implica a qualificação do corpo como marcado pelo desejo, pela concupiscência, sede da luxúria, das intensidades múltiplas de prazer e deleite. As novas técnicas de exame e direção espiritual vão fazer dessa interioridade objeto de discurso e de investigação analítica do corpo, que passa a ser culpabilizado pela carne. Dessa maneira, o saber-poder efetivado pela direção espiritual, pelo governo das almas, vai além do "controle tradicional das relações proibidas (adultérios, incestos, sodomia, bestialidade), pois passa a ser "acompanhado pelo controle da 'carne' nos movimentos elementares da concupiscência” (Foucault, 2001, p. 416). Em outras palavras, o pecado não se restringe aos atos, pois envolve também os pensamentos e as intençóes. "Agora o pecado da carne mora no interior do próprio corpo. É interrogando [...] as diferentes partes do corpo, é interrogando as diferentes instâncias sensíveis do corpo que vamos poder acuar o pecado da carne" (Foucault, 2001, p. 238).

Essa concepção faz com que a "forma primeira do pecado contra a carne é ter tido contato consigo mesmo: é ter se tocado, é a masturbação" (Foucault, 2001, p. 237). Pertinente notar que em $O$ cuidado de si (Foucault, 1984b), terceiro volume da História da sexualidade, Foucault chama a atenção para o "discreto lugar" que a masturbação ocupa em toda reflexão moral da Antiguidade grega e latina sobre a atividade sexual e também para sua valorização, sua "forma positiva": tratar-se-ia de um gesto de purgação das necessidades elementares do corpo, livre de qualquer relação com a "inutilidade do desejo, das imagens e do prazer” (Foucault, 1984b, pp. 164-165).

Foucault destacará ainda o surgimento, em meados do século XVIII, de uma série de textos, livros, panfletos e anúncios em que o discurso sobre a masturbação não faz menção a termos como "concupiscência", luxúria ou desejo e nem articula especificamente a masturbação com a sexualidade, em sua forma geral. Nesse sentido, esse novo discurso se distinguiria do discurso cristão da carne e o do discurso médico da psicopatologia sexual de meados do século XIX. Ele se localizaria "entre" esses dois, uma vez que assume a forma de uma "verdadeira campanha", de uma "cruzada" empreendida por uma literatura expressa em manuais de conselhos e exortações dirigidos aos pais e às próprias crianças e adolescentes burgueses sobre as consequências desastrosas da masturbação (Foucault, 2001, pp. 293-298). 
Essa campanha antimasturbatória não se configuraria tanto como uma "moralização", mas sim como uma "somatização", uma "patologização" da masturbação. Em outras palavras, a masturbação afeta, incide sobre o corpo inteiro e torna-se a causa de "todas as doenças possíveis", desde a meningite, a encefalite, a tuberculose, as doenças dos olhos e dos ossos e também a loucura (Foucault, 2001, pp. 301-304). Com isso se estabelece uma "espécie de etiologia histórica, com responsabilidade do próprio doente por sua doença: se você está doente, é porque quis; se seu corpo foi atingido, é porque você o tocou" (Foucault, 2001, p. 306).

Em razão dessa perspectiva, a criança (o "adulto em potência") passa a ser visada e responsabilizada, por toda a sua vida, por suas doenças e por sua morte. Por isso era "preciso vigiar as crianças desde o berço". De acordo com Foucault, elas eram responsabilizadas, mas não verdadeiramente culpadas. "A causa da masturbação mais frequentemente invocada pela cruzada é a sedução, a sedução pelo adulto: a culpa vem do exterior" (Foucault, 2001, p. 308). Assim, desde o início a campanha contra a masturbação, focaliza-se nos adultos que constituem o entorno das crianças: os criados, as babás, as governantas, os professores, os tios, os primos. Em última instância, a culpa seria dos pais, que não queriam cuidar diretamente de seus filhos, o que favoreceria o acontecimento dessas situações.

Desse modo, a campanha induz a um questionamento do papel dos pais e da relação entre pais e filhos no espaço familiar. Espaço que deve ser de vigilância continua na hora do banho, de acordar, de deitar. "Em torno das crianças, em suas roupas, em seu corpo, os pais devem estar à espreita. $\mathrm{O}$ corpo da criança deve ser objeto de atenção permanente" (Foucault, 2001, p. 311). Essa proximidade infinita dos pais com seu olhar, sua presença, seu contato, leva, segundo Foucault, à constituição de um "novo corpo familiar", "objetivo central da cruzada" (Foucault, 2001, p. 314). Essa nova família é o "agente transmissor do saber médico" sobre os malefícios da masturbação, sendo aparelhada com "toda uma técnica de poder, de que a medicina e os médicos são os transmissores junto às famílias”. (Foucault, 2001, p. 324). A nova família passa, portanto, a se encarregar do corpo e da vida dos filhos, como demandam as novas relaçóes de produção e o Estado, a fim de garantir tanto a sobrevivência das crianças quanto sua educação e seu desenvolvimento dentro nas normas saudáveis.

\section{O CORPO HIGIÊNICO E O CORPO SOCIAL}

Em 1976, é publicado o primeiro volume da História da sexualidade: a vontade de saber. 'Trata-se de uma obra que aborda vários temas e questôes, funcionando,

7 A vontade de saber é também o título do primeiro curso de Foucault no Collège de France, em 1970 e 1971 . Cabe destacar que, marcadamente influenciado por Nietzsche, Foucault recorrerá a uma série de textos da Grécia antiga, desde Homero, Platão, os 
ao mesmo tempo, como "introdução" e "primeira abordagem" de uma série de estudos históricos, que se concentrariam principalmente no período entre os séculos XVI e XIX e que resultariam em seis volumes. ${ }^{8}$

Esse projeto hipotético, que Foucault considerava um “jogo", 9 sofreu, como sabemos, profundas modificações temáticas e cronológicas que levaram à publicação, apenas em 1984, de $O$ uso dos prazeres (vol. 2) (Foucault, 1984a) e O cuidado de si (vol. 3) (Foucault, 1984b)..$^{10}$

Um dos pontos nodais de $A$ vontade de saber é o que Foucault nomeia como dispositivo de sexualidade. Esse dispositivo histórico, cuja emergência é contemporânea à das ciências humanas, é uma "produção originária e historicamente burguesa" (Foucault, 1976, p. 168). Trata-se de uma rede trançada por um conjunto de práticas, discursos e técnicas de captação dos corpos, estabelecida como um meio de afirmação da burguesia, que não desqualificou seu corpo, instituindo-o antes como fonte de cuidado. Se anteriormente a nobreza se distinguia pelo "sangue", a burguesia marcou sua hegemonia, atribuindo-se um corpo específico, saudável e higiênico. A valorização de seus prazeres e a proteção de seu corpo, além de garantirem seu vigor, descendência e longevidade, serviam como emblema de respeito e poder social. Afinal, diz Foucault, a supremacia da burguesia, além de depender da exploração econômica, requeria uma dominação física, já que "uma das formas primordiais da consciência de classe é a afirmação do corpo; [...] [a burguesia] converteu o sangue azul dos nobres em um organismo são e uma sexualidade sadia" (Foucault, 1976, p. 166).

Ele afirma também que a "história do dispositivo de sexualidade pode valer como uma arqueologia da psicanálise" (Foucault, 1976, p. 172). Percebe ainda que, além de desqualificar a representação jurídica, negativa e repressiva do poder, estava formulando uma "crítica bem mais radical": a crítica à teoria do desejo (Foucault, 1976, p. 107). ${ }^{11}$ Essa crítica, contudo, será efetivamente desenvolvida apenas nos segundo e terceiro volumes, quando reorganiza todo o conjunto "em torno da lenta formação, durante a Antiguidade, de uma hermenêutica de si” (Foucault, 1984a, p. 12). ${ }^{12}$

sofistas, Aristóteles e Sófocles, para explicitar as relações entre a verdade, o poder e o direito. Muitas dessas referências somente serão retomadas em 1984, nos dois últimos volumes da História da Sexualidade.

8 Ver nota 6.

9 "Jogo" é uma palavra que Foucault utiliza para nomear a proposta de $A$ vontade de saber. J-A. Miller e outros psicanalistas entrevistaram Foucault para a revista Ornicar? (n. 10), assim que o livro foi publicado. A entrevista foi intitulada de Le jeu de M. Foucault. A tradução brasileira encontra-se em Microfisica do poder, com o título "Sobre a história da sexualidade".

$10 \mathrm{O}$ quarto volume do novo projeto da História da sexualidade se intitula As confissóes da carne e focaliza o estudo da formação da doutrina e da pastoral da carne nos séculos IV e V d.C. Apesar de já ter bastante material redigido, o livro acabou não sendo publicado durante a vida de Foucault.

11 Foucault considera que tanto os reicheanos, partidários da temática da "repressão" (que concebe o desejo como algo estranho e exterior ao poder), quanto os lacanianos, partidários da teoria da "lei" (que estabelece o poder como constitutivo "do desejo e da falta que o instaura" - Foucault, 1976, p. 108), apesar de distintos na "maneira de conceber a dinâmica e a natureza das pulsões", são solidários no modo de representar o poder (Foucault, 1976, pp. 107-109)

12 O curso do Collège de France, nos anos 1981 e 1982, se intitula $A$ hermenêutica do sujeito e fornece boa parte do conteúdo dos volumes 2 e 3 da História da sexualidade, respectivamente, $O$ uso dos prazeres e $O$ cuidado de si. 
Essa perspectiva viabilizará que, na Modernidade, a sexualidade se torne uma referência fundamental no processo de produção da verdade e da subjetividade dos indivíduos:

[...] segundo círculos cada vez mais estreitos, o projeto de uma ciência do sujeito começou a gravitar em torno da questão do sexo. A causalidade no sujeito, o inconsciente do sujeito, a verdade do sujeito no outro que sabe, o saber, nele, daquilo que ele próprio ignora, tudo isso foi possível desenrolar-se no discurso do sexo. Contudo, não devido a alguma propriedade natural inerente ao próprio sexo, mas em função das táticas de poder imanentes a tal discurso (Foucault, 1976, p. 94).

A hipótese de Foucault é clara: a emergência da ciência do sujeito faz parte da expansão do dispositivo de sexualidade, que abre novas possibilidades para a infiltração do poder nos aspectos mais singulares da vida cotidiana. Assim, o que parecia ser liberação do silêncio imposto por um poder "repressivo", participação dos sujeitos no processo de sua constituição, revela-se um insidioso mecanismo de sujeição. Trata-se de uma forma individualizante de poder, que, classificando os indivíduos em categorias, fixa-os à sua própria identidade. Ela "transforma os indivíduos em sujeito", e Foucault considera que há dois sentidos para a palavra "sujeito": "sujeito submetido ao outro pelo controle e dependência, e sujeito fixado à sua própria identidade pela consciência ou conhecimento de si. Nos dois casos, a palavra sugere uma forma de poder que subjuga e sujeita" (Foucault, 1994, p. 227).

Além disso, o dispositivo de sexualidade exerce função estratégica em diferentes relações, seja entre homens e mulheres, pais e filhos, padres e leigos, administração pública e população. Essa flexibilidade permite-lhe não requerer espaços institucionais bem delimitados e servir de ponto de apoio e articulação aos mais variados objetivos, viabilizando uma série de intervenções em nível mais abrangente e global (Foucault, 1976, p. 192). Por isso, a sexualidade é também tema de interesse público, pois se encontra no centro de muitas questóes ligadas à população que, por estar relacionada à produção de riquezas, ao povoamento e à força de uma sociedade, constituiu-se, a partir do século XVIII, em importante problema econômico e político. A conduta sexual da população, por dizer respeito à saúde coletiva, à vitalidade das descendências e da espécie, torna-se objeto de análise e de diferentes projetos governamentais. Assim, o sexo passa a ser regulado não pelo rigor de uma proibição, mas por "discursos úteis e públicos" (Foucault, 1976, pp. 35-37).

Essa perspectiva faz dele um importante "princípio regulador" da população, dando margem a intervençóes que visam, principalmente por meio de grandes campanhas, a todo o corpo social. Essa forma de poder, que não se exerce pela 
força e ameaça de morte, mas pela vida e a partir da vida, é denominada por Foucault de "biopolítica da população" (Foucault, 1976, pp. 182-191).

Em $A$ vontade de saber, Foucault já havia contraposto à "ciência sexual" do Ocidente (cuja matriz é dada pela "confissão") outro procedimento de produção da verdade do sexo, a "arte erótica", praticada, por exemplo, na China ou na Índia. Nela, a verdade é extraída não de um discurso sobre o sexo, mas da própria prática sexual, que visa fundamentalmente ao prazer, considerado em relação a si mesmo, ou seja, segundo sua intensidade, sua duração e seus efeitos sobre o corpo e a alma (Foucault, 1976, pp. 76-78). No fim do livro, ele indica, ainda sem desenvolver, que "contra o dispositivo de sexualidade, o ponto de apoio do contra-ataque não deve ser o sexo-desejo, mas os corpos e os prazeres" (Foucault, 1976, p. 208).

\section{$4 \mathrm{O}$ corpo e as artes da existência}

Foucault reconheceu, posteriormente, a inadequação em estabelecer comparações entre civilizações tão diferentes, como a oriental e a ocidental. A partir do seu interesse pelas "técnicas ou práticas de si" (exercícios, regimes de saúde, meditações, exame de consciência, leituras, diários), sua pesquisa direcionou-se para um momento histórico, na própria civilização ocidental, em que o desejo não era ainda o foco das problematizações sexuais: a Antiguidade grega e greco-romana.

A teoria do desejo, já questionada, como apontamos, em $A$ vontade de saber, torna-se agora o alvo principal de seu empreendimento genealógico, que se dirige para a análise das "práticas pelas quais os indivíduos foram levados a prestar atenção a eles próprios, a se decifrar [...] como sujeitos de desejo, estabelecendo de si para consigo uma certa relação que lhes permite descobrir, no desejo, a verdade de seu ser" (Foucault, 1984a, p. 11).

Sob a mira da suspeita de Foucault está, portanto, a identificação do sujeito sexual ao "sujeito desejante", pois, para ele, o desejo não é algo constante, a-histórico, mas uma categoria isolada somente a partir da experiência cristã da carne (como marca originária da natureza decaída) e herdada pela experiência moderna da sexualidade, como estrutura própria ao ser humano (Foucault, 1984a, pp. 51-53). ${ }^{13}$

13 J-A Miller (1989) considera que, na época de $A$ vontade de saber, Foucault precisou de "um componente da perversão" ("a utopia de um corpo livre do sexo, cujos prazeres múltiplos não são reunidos sob o comando unificador da castração") para pensar um "de fora da psicanálise". No entanto, segundo Miller, a "arte erótica" mostrou-se frágil como ponto de apoio inicial para realizar um "contra-ataque ao sexo-desejo". Por isso, Foucault teria sido levado a retroceder historicamente em suas pesquisas, até encontrar, na Antiguidade grega, a utopia realizada, não de uma sexualidade feliz, mas de um corpo de prazer plural, onde as coisas do amor não formavam um conjunto unificado pela função do falo (Miller, 1989, pp. 77-84). 
Por outro lado, uma nova questão ganhou destaque: como e por que a conduta sexual e os prazeres a ela ligados tornaram-se o mais importante objeto de "preocupação moral" e de "cuidado ético"? (Foucault, 1984a, pp. 15-16).

Em suas análises dos textos dos filósofos, médicos e moralistas da Antiguidade grega e latina, ele perceberá que a problematização moral da atividade sexual enfatizava as "artes da existência", por ele definidas como "práticas refletidas e voluntárias através dos quais os homens não somente se fixam regras de conduta, como também procuram transformar-se [...] e fazer de suas vidas uma obra portadora de valores estéticos, respondendo a certos critérios de estilo" (Foucault, 1984a, pp. 16-17).

Nesse sentido, o cuidado de si do homem grego livre não implica uma volta para o "interior de si", em atitude de exame, exploração e suspeita, mas em um trabalho orientado para "fora de si", visando à configuração de uma superfície, à elaboração criativa de uma obra. Fazer da vida uma obra de arte era o objetivo de uma minoria privilegiada, formada pelos adultos livres do sexo masculino, que, liberada da tarefa de reprodução material da sociedade, podia valorizar, em sua maneira de viver, certos princípios gerais no uso dos prazeres, na distribuição que deles se faz, nos limites que se observa. É esse objetivo que explica, segundo Foucault, por que a reflexão moral, nesse momento, não se orientou para a codificação dos atos nem para uma hermenêutica do sujeito. Essa "moral de homens feita para homens" constituiu-se, sobretudo, em uma maneira de estilizar uma liberdade, na busca da produção de uma existência bela, assegurando o renome e a memória dos outros. ${ }^{14}$

Essa perspectiva das "artes de viver" faz com que, nos dois últimos volumes da História da sexualidade, a temática do corpo e da saúde seja novamente contemplada. ${ }^{15}$ No entanto não se trata mais de um "corpo útil, dócil ou higiênico", produzido e regulado pelas "técnicas disciplinares", mas de um corpo que se constituirá a partir das "técnicas ou práticas de si". Pautado nessa nova perspectiva, Foucault deixará de se interessar pelos procedimentos de sujeição e passará a estudar as "formas de subjetivação ou ética". ${ }^{16}$

Em $O$ uso dos prazeres, o capítulo "Dietética" (que trata da "arte da relação cotidiana do indivíduo com o próprio corpo") mostra como, na cultura grega clássica, procurou-se definir um regime para a atividade sexual (suas condições favoráveis, sua justa distribuição), em razão de certa maneira de o indivíduo cuidar ativamente de seu corpo, buscando integrar, o melhor possível, o

\footnotetext{
14 Para um contraponto às críticas de que Foucault, com a valorização da "estética da existência", teria cedido à "tentação narcísica" ou a um "dandismo da singularidade" (Gros, 2006, pp. 642-652; Cirino, 1992, pp. 49-50).

15 Além da Dietética, os outros núcleos de problematização das "artes de viver", em $O$ uso dos prazeres, são a Econômica ("arte da conduta do homem enquanto chefe de família") e a Erótica ("arte da conduta recíproca entre o homem e o rapaz livre na relação de amor"). Já em $O$ cuidado de si, esses aspectos são abordados com os seguintes títulos: O corpo, A mulher e Os rapazes. 16 Para um exame mais detalhado dessa mudança de perspectiva na obra de Foucault, ver Cirino (1989).
} 
comportamento sexual à gestão da vida e da saúde. Apesar de sua importância, Foucault não deixa de notar que o regime da atividade sexual ocupa "lugar limitado" em comparação com o regime alimentar, reconhecendo como "um traço comum à toda medicina grega e romana" a concessão de "muito mais espaço à dietética da alimentação do que à do sexo. Para ela, a grande questão é comer e beber" (Foucault, 1984b, pp. 165-166).

Percorrendo textos de Hipócrates, Platão, Aristóteles, Xenofonte, entre outros, Foucault constata que, na reflexão grega, a "dieta" ou "regime" implica um modo de viver cujas formas, escolhas e variáveis são determinadas pelo cuidado com o corpo. O regime deve contemplar numerosos elementos da vida física de um homem: os exercícios, os alimentos, as bebidas, os sonos; todos pautados "na justa medida" não somente na ordem corporal, mas também na ordem moral. Entre os exercícios, distinguem-se os naturais (andar, passear) dos violentos (a corrida, a luta), bem como quais são os que convém praticar e com que intensidade, de acordo com a hora do dia, a idade do sujeito e a alimentação. Aos exercícios relacionam-se os banhos, que podem ser mais ou menos quentes, dependendo das situaçôes. Já o regime alimentar (comida e bebida) deve considerar a natureza dos alimentos, suas qualidades e a quantidade do que se absorve, o clima e as atividades exercidas, sendo que as evacuações (purgações e vômitos) podem servir para corrigir os excessos alimentares. Também o regime do sono pode variar de acordo com o tempo que lhe é consagrado, a qualidade do leito, o modo de se deitar (Foucault, 1984a, p. 115-116).

Foucault destaca ainda que, na reflexão grega, o rigor do regime físico, com a resolução que é exigida para segui-lo, demanda uma indispensável "firmeza moral", como deixa clara a frase recortada da República de Platão: não basta "ser forte, são e belo, se com isso não se tornar temperante" (Foucault, 1984a, p. 118).

Com a prática do regime não se pretende contornar a fatalidade ou os limites da vida, mas sim permitir que se reaja, da melhor maneira possível, de uma forma racional e útil, às circunstâncias e aos acontecimentos imprevisíveis da vida. Em suma, diz Foucault:

A prática do regime como arte de viver é bem outra coisa do que um conjunto de precauções destinadas a evitar as doenças ou terminar de curá-las. É toda uma maneira de se constituir como um sujeito que tem por seu corpo o cuidado justo, necessário e suficiente. Cuidado que atravessa a vida cotidiana; que faz das atividades maiores ou rotineiras da existência uma questão, ao mesmo tempo, de saúde e de moral; que define entre o corpo e os elementos que o envolvem uma estratégia circunstancial; e que, enfim, visa a armar o próprio indivíduo com uma conduta racional (Foucault, 1984a, p. 123).

Já nos textos dos filósofos e médicos dos primeiros séculos da época imperial, 
como Sêneca, Plutarco, Galeno, Epicteto, Marco Aurélio, entre outros, Foucault constata que a "arte da existência", no mundo helenístico e romano, foi dominada pelo princípio do "cuidado de si”. Essa intensificação e valorização da relação para consigo passa então a comandar o desenvolvimento e organizar a prática da "arte de viver" (Foucault, 1984b, p. 58). Se "o cuidado de si" já era um tema da reflexão grega, nos primeiros séculos de nossa era, ele adquiriu as dimensões e as formas de uma verdadeira "cultura de si", pois circulou em diferentes doutrinas, tornou-se um princípio válido para todos durante toda a vida, desenvolveu-se em práticas que eram aperfeiçoadas e ensinadas, proporcionando um certo modo de conhecimento e elaboração de um saber (Foucault, 1984b, p. 59). Por isso, essa atividade consagrada a si mesmo não se constituiu, segundo Foucault, em "um exercício de solidão, mas sim em uma verdadeira prática social" (Foucault, 1984b, p. 67).

A estreita correlação que o princípio do "cuidado de si” mantém, já na cultura grega, com a prática e o pensamento médicos agora se intensifica e, com isso, uma atenção mais constante e vigilante é direcionada ao corpo e sua possível fragilidade. Ocorre também maior aproximação com o pensamento filosófico, uma vez que "formar-se e cuidar-se são atividades solidárias" (Foucault, 1984b, p. 71). Medicina e filosofia partilham então um conjunto comum de noções cujo "elemento central" é o conceito de pathos, que possibilitou a construção de "uma grade de análise válida para os males do corpo e da alma":

[Ele] tanto se aplica à paixão como à doença física, à perturbação do corpo como ao movimento involuntário da alma; num caso como no outro, refere-se a um estado de passividade que, para o corpo, toma a forma de uma afecção que perturba o equilíbrio de seus humores ou de suas qualidades e que, para a alma, toma a forma de um movimento capaz de arrebatá-la (Foucault, 1984b, p. 70).

Os prazeres sexuais são alvo de valorizações antitéticas, marcadas por uma ambivalência, que o título dado por Foucault à segunda parte do capítulo IV de O cuidado de si delimita com perfeição: "Seriam eles bons, seriam maus?". Em outras palavras, os efeitos das relações sexuais ou de sua abstenção sobre o corpo podem tanto ser curativos quanto patológicos.

Nesse sentido, o regime proposto para os prazeres sexuais, ainda que concedendo privilégio ao corpo (seu estado, seus equilíbrios, suas afecções e disposições), não deixa de considerar o papel da alma, pois é ela que pode fazer o sujeito correr o risco de ser arrebatado para além das necessidades elementares do corpo, incitando-o a escolher momentos inapropriados ou a agir em circunstâncias suspeitas, contrariando as disposições naturais. Por isso um bom regime somático depende de um labor da alma racional sobre ela própria, reduzindo as imaginaçôes, dominando os desejos e considerando o prazer como 
algo que acompanha o ato e não como a razão de realizá-lo (Foucault, 1984b, p. 157). Não se trata, contudo, como esclarece Foucault, de instaurar uma luta da alma contra o corpo, como na experiência cristã da carne, mas da alma "corrigirse para poder conduzir o corpo segundo uma lei que é a do próprio corpo" (Foucault, 1984b, p. 158).

Estabelecendo contraponto com a reflexão grega, Foucault considera que, na época helenística, a mudança na dietética e na problematização da saúde se deu por meio de "uma definição mais extensa e detalhada das correlações entre o ato sexual e o corpo, uma atenção mais viva à ambivalência de seus efeitos e a suas consequências perturbadoras", que faz com que ele se aparente com a doença e o mal, só que, diferentemente da moral cristã que se efetivará mais tarde, a atividade sexual não é em si mesma e substancialmente um mal. (Foucault, 1984b, pp. 272-273)

\section{A excelência da atividade filosófica}

Situar os diferentes momentos e abordagens empreendidas por Foucault em torno da temática do corpo significa acompanhar o exercício de um pensamento que é capaz de "separar-se de si mesmo", a fim de responder não somente aos obstáculos de suas investigações, mas ao apelo de novas questões. As modificações metodológicas, as mutaçōes de problemática e a revolução conceitual que percorrem sua obra, longe de assinalarem falta de rigor intelectual, uma atração pelo modismo ou simples vontade de provocar alarde nos meios acadêmicos, atestam a fidelidade ao que Foucault considera ser, por excelência, a atividade filosófica na atualidade; um trabalho crítico do pensamento sobre o próprio pensamento (Foucault, 1984a, p. 14). 


\section{REFERÊNCIAS}

Cirino, O. (1989). Sujeçção e subjetivação: a genealogia do sujeito em M. Foucault. (Dissertação de Mestrado). Programa de Pós-graduação em Filosofia, Universidade Federal de Minas Gerais, Belo Horizonte.

Cirino, O. (1992). História da sexualidade: um exemplo de inquietação intelectual. Extensão, 2(1), 31-52.

Dreyfus, H. \& Rabinow, P. (1984). Michel Foucault: un parcours philosophique. Paris: Gallimard.

Eribon, D. (1990). Michel Foucault (1926-1984). São Paulo: Companhia das Letras.

Foucault, M. (1975). Surveiller et punir. Paris: Gallimard.

Foucault, M. (1976). Histoire de la sexualité: la volonté de savoir. (Vol. 1). Paris: Gallimard.

Foucault, M. (1980). O nascimento da clínica. Rio de Janeiro: ForenseUniversitária.

Foucault, M. (1982). Nietzsche, a genealogia e a história. In M. Foucault, Microfisica do poder. (pp. 15-37). Rio de Janeiro: Graal.

Foucault, M. (1984a). Histoire de la sexualité: l'usage des plaisirs. (Vol. 2). Paris: Gallimard.

Foucault, M. (1984b). Histoire de la sexualité: le souci de soi. (Vol. 3). Paris: Gallimard.

Foucault, M. (1985). As palavras e as coisas. São Paulo: Martins Fontes.

Foucault, M. (1994). Le sujet et le pouvoir. In M. Foucault, Dits et écrits. (Vol. 4). Paris: Gallimard.

Foucault, M. (2001). Os anormais. São Paulo: Martins Fontes.

Foucault, M. (2006a). A hermenêutica do sujeito. São Paulo: Martins Fontes.

Foucault, M. (2006b). O poder psiquiátrico. São Paulo: Martins Fontes.

Gros, F. (2006). Situação do curso. In M. Foucault, $A$ hermenêutica do sujeito. (pp. 613-661). São Paulo: Martins Fontes. 
Lacan, J. (1998). Variantes do tratamento-padrão. In J. Lacan, Escritos. (pp. 325-364). Rio de Janeiro: Jorge Zahar.

Lagrange, J. (2006). Situação do curso. In M. Foucault, O poder psiquiátrico. (pp. 455-478). São Paulo: Martins Fontes.

Machado, R. (1982). Por uma genealogia do poder. In M. Foucault, Microfísica do poder. (pp. VII-XXIII). Rio de Janeiro: Graal.

Miller, J-A (1989). M. Foucault et la psychanalyse. In J-A. Miller, M. Foucault, Philosophe. (pp. 77-84). Paris: Seuil. 